\title{
Unidade de Ensino Potencialmente Significativa por meio de experimentos com cinza de casca de arroz
}

\author{
Antonio Vanderlei dos Santos*, Gabriela Benchimol Garcia ${ }^{\star *}$, \\ Bruna Teresinha Klassen Tusset ${ }^{\star \star \star}$, Rozelaine de Fátima Franzin ${ }^{\star \star \star \star}$, \\ Marcelo Paulo Stracke ${ }^{\star \star \star \star \star}$, Giselda Aparecida Ghislene ${ }^{\star \star \star \star \star \star}$, Vitor Cauduro Girardello
}

\section{Resumo}

Este trabalho apresenta a utilização da cinza de casca de arroz na produção de soja como Unidade de Ensino Potencialmente Significativa (UEPS), e a sua aplicação no ensino de Ciências/ Química. Trata-se de uma metodologia de ensino visando à aprendizagem, com alunos mais participativos e atuantes na aula, e o professor como parte integrante desse processo. A aplicação desta estratégia também contribui para ultrapassar a aprendizagem mecânica, ainda bastante presente nas aulas. Com este trabalho, objetiva-se construir uma UEPS afim de facilitar a aprendizagem significativa da reação de equilíbrio químico envolvendo as moléculas de água e a sílica incorporada ao solo em diferentes doses.

Palavras-Chave: UEPS. Cinza de casca de arroz. Ensino.

* Universidade Regional Integrada do Alto Uruguai e das Missões, URI-Santo Ângelo, Departamento de Engenharias e Ciência da Computação; Curso de Engenharia Química. E-mail: vandao@santoangelo.uri.br

* Universidade Regional Integrada do Alto Uruguai e das Missões, URI-Santo Ângelo, Departamento de Engenharias e Ciência da Computação; Curso de Engenharia Química. E-mail: gabrielabenchimol96@gmail.com

*** Universidade Regional Integrada do Alto Uruguai e das Missões, URI-Santo Ângelo, Departamento de Engenharias e Ciência da Computação; Curso de Engenharia Química. E-mail: brunaklassen@yahoo.com.br

*t** Universidade Regional Integrada do Alto Uruguai e das Missões, URI-Santo Ângelo, Departamento de Engenharias e Ciência da Computação; Curso de Engenharia Química. E-mail: rozelaine@santoangelo.uri.br

..... Universidade Regional Integrada do Alto Uruguai e das Missões, URI-Santo Ângelo, Departamento de Engenharias e Ciência da Computação; Curso de Engenharia Química. E-mail: stracke@santoangelo.uri.br

*..-** Universidade Regional Integrada do Alto Uruguai e das Missões, URI-Santo Ângelo, Departamento de Engenharias e Ciência da Computação; Curso de Engenharia Química. E-mail: giselda@san.uri.br

*..**** Universidade Regional Integrada do Alto Uruguai e das Missões, URI-Santo Ângelo, Departamento de Engenharias e Ciência da Computação; Curso de Engenharia Química. E-mail: vitorgirardello@san.uri.br

Recebido em: 23/08/2019 - Aceito em: 10/10/2019.

https://doi.org/10.5335/rbecm.v2i2.9807 


\section{Introdução}

A estratégia de ensino desse trabalho está fundamentada na Teoria da Aprendizagem Significativa, e na construção de uma Unidade de Ensino Potencialmente significativa (UEPS) envolvendo a utilização da cinza de casca de arroz como meio de absorção de moléculas de água baseado numa reação de equilíbrio químico. $\mathrm{O}$ estudo da química possibilita ao homem o desenvolvimento de uma visão crítica do mundo que o cerca, podendo analisar, compreender e utilizar este conhecimento no cotidiano, tendo condições de perceber e interferir em situações que contribuam para a deterioração de sua qualidade de vida, como por exemplo, o impacto ambiental provocado pelos rejeitos industriais e domésticos, que poluem o ar, a água e o solo (CARDOSO e COLINVAUX,2000).

A aprendizagem significativa é um processo pelo qual uma nova informação se relaciona com os conhecimentos prévios dos estudantes a partir de suas vivências, denominados, por ele, de subsunçores (AUSUBEL, 1982). Assim, a aprendizagem significativa ocorre quando o novo conhecimento se ancora nos conhecimentos prévios. Quanto mais ampla e mais significativa for a aprendizagem, mais diferenciados serão os subsunçores (AUSUBEL et al., 2000). Para a elaboração da Unidade de Ensino Potencialmente Significativa, a aprendizagem deve ser significativa e crítica (MOREIRA, 2011).

A aprendizagem significativa é utilizada para avaliar a aprendizagem de laboratório e para investigar os domínios afetivo, cognitivo e psicomotor da experiência de aprendizagem do aluno (GEORGE-WILLIAMS et al., 2019), mostrando assim a versatilidade de trabalhos propostos com o uso da teoria. Para compreender a teoria é preciso experienciá-la (FREIRE, 1997). Cerca de 80\% conseguiram relacionar a prática com exemplos do seu cotidiano, havendo uma melhor compreensão do que está sendo estudado. A prática articulada à teoria faz muita diferença para um ensino contextualizado, no qual os alunos conseguem perceber a importância dos conteúdos ensinados, proporcionando maior clareza para que possam realmente interpretar, buscando a participação ativa do estudante na resolução de situações problemáticas. Trabalhar com a experimentação significa criar um ambiente propício para a investigação, em que o aluno faça parte ativamente da construção da aprendizagem, investigue, analise, crie hipóteses, discuta e trabalhe em grupo, envolvendo-o, assim, na busca por conclusões que sustentem sua teoria (GUIMA- 
RÃES, 2009). Essa metodologia torna o ensino realmente ativo, envolvendo alunos na manipulação direta de materiais e na realização de experimentos nos quais eles possam modificá-los, testá-los e interpretá-los (MORAES e RAMOS, 1988).

O uso de materiais alternativos, de fácil aquisição e/ou de baixo custo, não é novidade nas instituições de ensino. Ao fazer uso de métodos alternativos, o professor estará colaborando para que os alunos consigam observar a importância da matéria, tornando a disciplina divertida e interessante, despertando o interesse e incentivando uma aprendizagem mais significativa (HORN, 2011). Materiais alternativos são recursos encontrados no cotidiano que podem ser utilizados como ferramentas de ensino, cujas principal característica está no fato de serem de baixo custo e de fácil aquisição. Esses materiais podem ser empregados como ferramentas de apoio no processo ensino-aprendizagem, sustentando a teorização de alguns conceitos fundamentais de maneira prática e experimental sem perder de vista a importância da fundamentação científica do conteúdo ensinado. $\mathrm{O}$ ato de interagir com materiais alternativos ativa a capacidade de desenvolver habilidades e competências, permitindo a ampliação do conhecimento e colocando a Ciência mais próxima das necessidades de aprendizagem do aluno. Portanto, a produção de uma sequência de ensino direcionada à aprendizagem viabiliza a inserção de discussões sobre ciência, tecnologia, sociedade e ambiente no contexto de ensino-aprendizagem, que são importantes à formação do cidadão crítico (SILVA, 2013).

A principal motivação científica do estudo foi o desenvolvimento de uma UEPS usando a problemática do ensino de química, por meio do resíduo da queima da casca de arroz (CA). A casca de arroz já é utilizada pelos engenhos de arroz como combustível nas fornalhas em substituição à lenha. Esta substituição justifica-se pela grande disponibilidade, custo reduzido e ainda pelo poder calorífico da casca de arroz, que é de 3730 kcal kg-1, comparável à acácia negra (4550 kcal kg-1) e ao Eucalyptus sp. (4525 kcal kg-1) (Quirino et al., 2005), mas inferior ao carvão vegetal, que apresenta valores em torno de $7500 \mathrm{kcal} \mathrm{kg-1} \mathrm{(Vale} \mathrm{et} \mathrm{al.,} \mathrm{2002).}$

$\mathrm{O}$ processo da queima da casca de arroz gera grande quantidade de casca de arroz (CCA), um resíduo inorgânico, em cerca de 20\% (OLIVEIRA et al., 2007). Para cada tonelada de arroz em casca, $40 \mathrm{~kg}$ correspondem a cinzas (DELLA; KÜHN e HOTZA, 2005). Como não há destinação consolidada a este subproduto, grande parte da CCA é depositada em lugares inapropriados ou em aterros sanitários, gerando grave problema ambiental. Por ser rica em sílica $\left(\mathrm{SiO}_{2}\right)$, alguns estudos 
foram desenvolvidos buscando utilizar a CCA na produção de refratários à base de sílica, vidros, cerâmicas, cimento, isolante térmico e carga em polímeros (NETO, 2007). Porém, mesmo com esses estudos, não houve acréscimo no volume de CCA utilizada, sendo necessárias mais pesquisas que busquem diminuir ou erradicar este passivo ambiental.

A CCA já está sendo utilizada, de forma empírica, por agricultores familiares, como corretivo e condicionante do solo (ISLABÃO, 2013). O uso de silício em culturas como o trigo, a soja, o milho e o feijão resultou em diversos benefícios para as plantas, como o aumento na produtividade, resistência a ataques de pragas e doenças, diminuição dos efeitos tóxicos de alguns elementos químicos, e tolerância ao estresse salino e hídrico (RODRIGUES et al., 2011).

Pesquisadores como Santin e Vahl (1985), Sandrini (2010), Islabão (2013) e Donega et al. (2007) constataram que a aplicação da CCA no solo apresenta potencial corretivo em relação ao $\mathrm{pH}$ e auxilia no suprimento de nutrientes, beneficiando o desenvolvimento das plantas e aumentando a produtividade das culturas.

ACCA é uma fonte alternativa de nutrientes para as plantas, contendo elementos como fósforo, enxofre (S), potássio (K), magnésio, cálcio e silício (KATO; OWA, 1997). A cinza de casca de arroz carbonizada apresenta aproximadamente $92 \%$ de silício (FOLETTO et al., 2005); sendo assim, pode vir a ser utilizada como fonte de silício devido ao alto teor do mesmo. Ainda do ponto de vista fisiológico, para o crescimento e o desenvolvimento das plantas, o silício tem mostrado efeito benéfico quanto ao aumento de produção de diversas culturas (GOMES et al., 2008). Na solubilização da sílica, ocorre a hidratação (KRAUSKOPF, 1972), conforme a reação de equilíbrio químico abaixo:

$$
\mathrm{SiO}_{2}+2 \mathrm{H}_{2} \mathrm{O} \leftrightarrow \mathrm{H}_{4} \mathrm{SiO}_{4}
$$

Desta forma, esta pesquisa tem como objetivo desenvolver uma UEPS utilizando os experimentos e desenvolvida com o uso da cinza da casca de arroz. Busca-se também comprovar a sua utilização como reservatório molecular de água e sílica para a produção de soja, propiciando, dessa maneira, que a planta tenha acesso a esse reservatório de acordo com a sua necessidade. 


\section{Material e métodos}

\section{Metodologia}

Este trabalho de pesquisa é de natureza aplicada, na medida em que construiu um modelo de utilização dos conceitos desenvolvidos. A pesquisa aplicada caracteriza-se por seu interesse prático, isto é, que os resultados sejam aplicados ou utilizados imediatamente na solução de problemas que ocorrem na realidade (TURRIONI e MELLO, 2012).

Quanto aos objetivos, a pesquisa normativa está primariamente interessada no desenvolvimento de estratégias e ações para aperfeiçoar o ensino de um tema, para encontrar uma solução ótima afim de obter novas definições de problemas ou para comparar várias estratégias relativas a um problema específico (BERTRAND e FRANSOO, 2002).

Quanto à forma de abordar o problema, classifica-se como pesquisa combinada, sendo que o pesquisador combinou aspectos das pesquisas quantitativas e qualitativas em algumas etapas (TURRIONI e MELLO, 2012). Quantitativa, quando traduziu em números as informações para analisá-las e classificá-las; qualitativa, por interpretar e atribuir significado às informações obtidas.

Em relação aos procedimentos técnicos utilizados, englobou aspectos de pesquisas bibliográficas, documental e de levantamento de experimentos nas instituições de ensino à cerca do problema estudado (GIL, 2002).

\section{Método de Desenvolvimento das UEPS}

O desenvolvimento da Unidade de Ensino Potencialmente Significativa foi realizada com cinco participantes: dois professores e três estudantes de uma Universidade. Os ensaios foram realizados na safra agrícola de 2017/2018, para a cultura da soja (Glicyne max). O desenvolvimento da UEPS começou com um relatório realizado pelos participantes, os quais responderam a duas questões dissertativas referentes às expectativas e aos motivos pelos quais optaram por fazer a oficina entre outras que foram oferecidas.

Para a análise da CCA e suas contribuições nutricionais para as culturas e os atributos agronômicos do solo, executou-se um procedimento e num bloco de 
parcelas experimentais no tamanho de $400 \mathrm{~m}^{2}$, tendo 16 parcelas experimentais de $25 \mathrm{~m}^{2}$ cada. $\mathrm{O}$ experimento se constituiu de um delineamento de bloco são acaso com quatro repetições, seguindo um esquema fatorial $4 \times 4$ para os fatores dose de formulação química e doses de CCA. Neste sentido, os fatores de tratamento usados caracterizaram-se pela combinação de doses de cinza de casca de arroz:

- T1 - Adubação de base 'AB', 500kg ha'-1 (4-24-12) no momento da semeadura.

- $\mathrm{T} 2$ - ( $\mathrm{AB}+1.200 \mathrm{~kg} \mathrm{ha}^{-1}$ decinza de casca de arroz).

- $\mathrm{T} 3-\left(\mathrm{AB}+1.800 \mathrm{~kg} \mathrm{ha}^{-1}\right.$ decinza de casca de arroz).

- $\mathrm{T} 4$ - ( $\mathrm{AB}+2.400 \mathrm{~kg} \mathrm{ha}^{-1}$ decinza da casca de arroz).

O plantio da soja (Glicyne max) efetuou-se no mês de novembro de 2017, sendo utilizada a cultivar TMG 7063 Inox ${ }^{\circledR}$ IPRO, com densidade de treze sementes por metro linear. A cinza de casca de arroz foi aplicada no solo a lanço, após a semeadura de cada bloco de parcelas.

A colheita da cultura da soja ocorreu no mês de abril de 2018, sendo escolhido um metro quadrado da área útil de cada parcela, totalizando, assim, as repetições para cada tratamento utilizado. Posteriormente encaminhado ao laboratório de recebimento de culturas, sendo preparadas para a análise.

As amostras de cinza de casca de arroz e de solo foram coletadas antes e após a colheita da cultura, sendo realizadas em duas profundezas, de 0,0-0,05 m e 0,05-0,10 m. Posteriormente, estas foram encaminhadas ao laboratório de solos da Universidade, sendo preparadas para as devidas análises.

Analisaram-se, tanto a campo como em laboratório, fatores que compõem a produtividade da cultura da soja, sendo: massa de mil grãos, número de vagens, número de grãos por vagem, número total de grãos por planta, vagem com três grãos, vagem com dois grãos e vagem com um grão.

Efetuou-se uma análise de variância para verificar as diferenças estatísticas de cada fator, assim como a possibilidade de interação entre os fatores de tratamento. Havendo diferenças significativas, testes de médias serão utilizados para classificar melhores doses de CCA e da adubação química por meio do teste de Tukey a um nível de $95 \%$ de confiança.

A expressão "física newtoniana" refere-se ao conjunto de contribuições de Isaac Newton para a Física. Nascido na Inglaterra em 1642, Newton formulou a Lei da Gravitação Universal, e as chamadas Três Leis de Newton sobre os movimentos. 
O Barroco foi um período do século XVI marcado pela crise dos valores Renascentistas, gerando uma nova visão de mundo através de lutas religiosas e dualismos entre espírito e razão. O movimento envolve novas formas de literatura, arte e até filosofia. A seguir será apresentado no Quadro 1 as principais teorias de aprendizado pela UEPS.

Quadro 1: Alguns princípios da Teoria da Aprendizagem Significativa (TAS) que precisam ser considerados pelo professor na construção de uma UEPS

(continua...)

\begin{tabular}{|c|c|}
\hline Princípios & Significados \\
\hline $\begin{array}{l}\text { Identificação dos } \\
\text { conhecimentos } \\
\text { prévios }\end{array}$ & $\begin{array}{l}\text { O que o aluno já sabe, o conhecimento prévio (conceitos, proposições, princípios, } \\
\text { fatos, ideias, imagens, símbolos), é fundamental para a TAS, uma vez que constitui-se } \\
\text { como determinante do processo de aprendizagem, pois é significativo por definição, } \\
\text { base para a transformação dos significados lógicos dos materiais de aprendizagem } \\
\text { potencialmente significativos. }\end{array}$ \\
\hline $\begin{array}{l}\text { Uso de organiza- } \\
\text { dores prévios }\end{array}$ & $\begin{array}{l}\text { O organizador prévio é uma estratégia que consiste na utilização de materiais auxi- } \\
\text { liares, antes do próprio material de aprendizagem, com a finalidade de criar pontos } \\
\text { de ancoragem, em nível mais geral do que o material mais detalhado que a precede. } \\
\text { Tais organizadores devem ser utilizados quando for constatado que os subsunçores } \\
\text { identificados não estão suficientemente claros ou encontram-se desorganizados para } \\
\text { desempenhar as funções de ancoragem. }\end{array}$ \\
\hline $\begin{array}{l}\text { Situações- } \\
\text { problema }\end{array}$ & $\begin{array}{l}\text { São as situações-problema que dão sentido a novos conhecimentos (Vergnaud, } \\
\text { 1990). Elas devem ser criadas para despertar a intencionalidade do aluno para a } \\
\text { aprendizagem significativa. Situações problema podem funcionar como organizado- } \\
\text { res prévios. As situações-problema devem ser propostas em níveis crescentes de } \\
\text { complexidade (ibid., 1990). }\end{array}$ \\
\hline $\begin{array}{l}\text { Diferenciação } \\
\text { progressiva }\end{array}$ & $\begin{array}{l}\text { O princípio da diferenciação progressiva, pelo qual o assunto deve ser programado } \\
\text { de forma que as ideias mais gerais e inclusivas da disciplina sejam apresentadas } \\
\text { antes e progressivamente diferenciadas, introduzindo os detalhes específicos neces- } \\
\text { sários - ordem de apresentação que corresponde à sequência natural da consciência } \\
\text { quando um ser humano é espontaneamente exposto a um campo inteiramente novo } \\
\text { de conhecimento. }\end{array}$ \\
\hline $\begin{array}{l}\text { Reconciliação } \\
\text { integrativa }\end{array}$ & $\begin{array}{l}\text { O princípio da reconciliação integrativa, pelo qual a programação do material de ensi- } \\
\text { no deve ser feita para explorar relações entre ideias, apontar similaridades e } \\
\text { diferenças significativas, reconciliando discrepâncias reais ou aparentes. }\end{array}$ \\
\hline $\begin{array}{l}\text { Abandono da } \\
\text { narrativa pelo } \\
\text { professor }\end{array}$ & $\begin{array}{l}\text { Narrar é um meio ineficaz (ibid. 2011a) para estimular a compreensão, ainda que } \\
\text { ocupe o primeiro lugar na lista daquilo que fazem os professores. Para ele, a boa } \\
\text { docência é aquela que cria circunstâncias que conduzem à aprendizagem relevante, } \\
\text { duradoura. Na educação, a primazia deve ser da aprendizagem, não do ensino. } \\
\text { Aprender é o objetivo e ensinar é um meio para este fim. }\end{array}$ \\
\hline $\begin{array}{l}\text { Ensino centrado } \\
\text { no aluno }\end{array}$ & $\begin{array}{l}\text { Ensino centrado no aluno, tendo o professor como mediador, é ensino em que o aluno } \\
\text { fala muito e o professor fala pouco. Deixar os alunos falarem implica usar estratégias } \\
\text { nas quais possam discutir, negociar significados entre si, apresentar oralmente ao } \\
\text { grande grupo o produto de suas atividades colaborativas, receber e fazer críticas. O } \\
\text { aluno deve ser ativo, não passivo. Ela ou ele tem que aprender a interpretar, a nego- } \\
\text { ciar significados; tem que aprender a ser crítico(a) e aceitar a crítica. }\end{array}$ \\
\hline
\end{tabular}


(conclusão)

\begin{tabular}{|c|c|}
\hline $\begin{array}{l}\text { Predisposição } \\
\text { para aprender }\end{array}$ & $\begin{array}{l}\text { É o aluno que decide se quer aprender significativamente ou não. Para aprender } \\
\text { significativamente, o aluno tem que manifestar uma disposição para relacionar, de } \\
\text { maneira não arbitrária e não literal (substantiva), à sua estrutura cognitiva, os signi- } \\
\text { ficados que capta a respeito dos materiais educativos, potencialmente significativos, } \\
\text { do currículo. Predisposição está relacionada à intencionalidade, um esforço delibe- } \\
\text { rado para relacionar os novos conhecimentos com os prévios mais consistentes e } \\
\text { sedimentados. }\end{array}$ \\
\hline $\begin{array}{l}\text { Avaliação da } \\
\text { aprendizagem }\end{array}$ & $\begin{array}{l}\text { A avaliação da aprendizagem significativa deve ser feita em termos de buscas de evi- } \\
\text { dências; a aprendizagem significativa é progressiva. Embora seja necessário atribuir } \\
\text { uma nota, a intenção é o acompanhamento processual, ou seja, como o aluno ao } \\
\text { longo da matéria, vai atribuindo e negocia os significados dos conceitos no contexto } \\
\text { escolar. }\end{array}$ \\
\hline $\begin{array}{l}\text { Organização } \\
\text { sequencial }\end{array}$ & $\begin{array}{l}\text { Como princípio a ser observado na programação do conteúdo para fins instrucionais, } \\
\text { consiste em sequenciar os tópicos, ou unidades de estudo, de maneira tão coerente } \\
\text { quanto possível (observados os princípios da diferenciação progressiva e da reconci- } \\
\text { liação integrativa) com as relações de dependência naturalmente existentes na ma- } \\
\text { téria de ensino. }\end{array}$ \\
\hline Consolidação & $\begin{array}{l}\text { O princípio da consolidação, por sua vez, é aquele segundo o qual insistindo-se no } \\
\text { domínio (ou mestria) do que está sendo estudado, antes que novos materiais sejam } \\
\text { introduzidos, assegura-se contínua prontidão na matéria de ensino e alta probabilida- } \\
\text { de de êxito na aprendizagem sequencialmente organizada. O fato de Ausubel chamar } \\
\text { atenção para a consolidação é coerente com sua premissa básica de que o fator } \\
\text { isolado mais importante influenciando a aprendizagem é o que o aprendiz já sabe. }\end{array}$ \\
\hline $\begin{array}{l}\text { Avaliação do } \\
\text { processo de } \\
\text { ensino }\end{array}$ & $\begin{array}{l}\text { A avaliação requer um olhar interno para a própria estrutura da metodologia, cuja } \\
\text { magnitude da tarefa torna-a ainda mais complexa, porém não inexequível. O papel } \\
\text { do professor é o de provedor de situações-problema, cuidadosamente selecionadas, } \\
\text { de organizador do ensino e mediador da captação de significados de parte do aluno. }\end{array}$ \\
\hline
\end{tabular}

Fonte: Adaptado de Ausubel (2003) e Moreira (2011a, 2011b, 2011c).

\section{Resultados e discussões}

Os participantes se mostraram motivados e participativos tanto nas atividades desenvolvidas nas UEPS como nas discussões feitas durante a realização da oficina. Primeiramente, foram desenvolvidas as atividades experimentais; posteriormente, foi aplicado um questionário como objetivo de verificar quais motivos levaram os participantes a tomar parte da oficina. O desenvolvimento da UEPS ocorreu ao longo do segundo semestre de 2017 e culminou com a sua apresentação na Vitrine Tecnológica, ocorrida no primeiro semestre de 2018 na área experimental da Universidade.

Entre as diferentes atividades desenvolvidas, destacamos aqui a Caracterização da Cinza da Casca de Arroz: por meio de análise de DRX das amostras de CCA, determinou-se que 91,7\% da composição desta é de sílica. A análise feita 
no Microscópio Eletrônico de Varredura (MEV) também confirmou que o material presente na CCA in natura consiste de Si e K, confirmando a presença de sílica nos componentes da cinza. O espectro MEV-EDS da cinza de casca de arroz apresentou em sua composição componentes como o silício ( $\mathrm{Si}$ ) e potássio, com uma porcentagem em massa de $91,8 \%$ de Si e de $8,2 \%$ de K, componentes importantes para o solo, tratando-se de fertilizantes. A cinza de casca de arroz obtida da empresa, possui - na sua composição - somente elementos benéficos sem a presença de elementos tóxicos, possibilitando a sua utilização na proposta metodológica de experimentação no solo.

Pelos resultados experimentais apresentados, em relação aos fatores referentes à produtividade da soja, como total de grãos por planta, vagens com dois grãos, vagem com um grão e vagens por planta, não foi observado diferença significativa com as diferentes doses de CCA $\left(0,1200,1800,2400 \mathrm{Kg}^{2}{ }^{-1}\right)$. Porém, em todos estes fatores, o tratamento com $2400 \mathrm{~kg} \mathrm{ha}^{-1}$ de CCA foi o que apresentou os melhores resultados, fazendo-se necessário ressaltar a resposta positiva da aplicação de CCA, pois mesmo não ocorrendo, estatisticamente, acréscimo nos valores destes atributos analisados, não houve prejuízo à cultura.

Tabela 1: Valores médios de produtividade, total de grãos por planta, vagem com dois grãos, vagem com um grão e vagens por planta, cultivar TMG 7063 IPRO

\begin{tabular}{l|r|r|r|r|r}
\hline $\begin{array}{c}\text { Doses } \\
\mathrm{Kg} \mathrm{ha}^{-1}\end{array}$ & $\begin{array}{c}\text { Produtividade } \\
\left(\mathrm{kg} \mathrm{ha}^{-1}\right)\end{array}$ & $\begin{array}{c}\text { Grãos por } \\
\text { Planta }\end{array}$ & $\begin{array}{c}\text { Vagem um } \\
\text { grão }\end{array}$ & $\begin{array}{c}\text { Vagem dois } \\
\text { grãos }\end{array}$ & $\begin{array}{c}\text { No vagem } \\
\text { por planta }\end{array}$ \\
\hline 0 & 4305 & 101 & 9 & 18 & 46 \\
1200 & 4080 & 101 & 11 & 17 & 47 \\
1800 & 4620 & 108 & 11 & 17 & 49 \\
2400 & 4995 & 132 & 9 & 21 & 57 \\
Média & 4500 & 110 & 10 & 18 & 49 \\
CV\% & 16,05 & 18,46 & 26,34 & 21,08 & 16,65 \\
Teste Tukey (5\%) & Ns & Ns & Ns & Ns & Ns \\
\hline
\end{tabular}

Sendo CV\%: Coeficiente de variação. ns: Não Significativo Teste de Tukey a 5\% de probabilidade.

Fonte: Os autores.

A produtividade média obtida neste experimento foi $57 \%$ superior à média de produção na região durante a safra 2016/17, que foi de $2.823 \mathrm{~kg} \mathrm{ha}^{-1}$, e $47 \%$ superior à doestado do Rio Grande do Sul (CONAB,2019). O tratamento com a maior dose (2400) obteve um incremento de $690 \mathrm{~kg}$ em decorrência do aumento das doses estudadas. Os componentes de rendimento não sofreram diferença estatística entre 
os parâmetros grãos por planta, vagens com ume dois grãos, e número de vagens por planta.

Este aumento na produtividade decorre do fato da presença de silício ser bastante elevada na CCA, contribuindo assim para o aumento da produtividade da cultura da soja. Essa informação corrobora os achados de Oliveira (2013), que, utilizando doses maiores nos tratamentos, obteve aumento da produtividade e melhor qualidade fisiológica na semente de soja, bem como melhor arquitetura folhar, permitindo assim um melhor aproveitamento fotossintético.

Já para os fatores massa de mil grãos e vagens com três grãos, houve diferença significativa (Tukey 5\%): nos dois casos, houve um crescimento linear com o acréscimo de doses de CCA.

Verifica-se que - para os fatores massa de mil grãos e vagens com três grãos-, o aumento gradativo de doses de tratamentos proporcionou um incremento na produção, pois, além de proporcionar grãos mais pesados, a utilização de CCA promoveu a produção de mais grãos por planta, o que resultará em maiores produtividades na cultura.

A seguir, são apresentadas as respostas transcritas dos participantes da oficina realizada durante a Vitrine Tecnológica, referente às seguintes perguntas:

a) Quais foram os motivos pelos quais optaram por fazer essa oficina?

- Participante 1 (Professor): Conhecer uma sequência de ensino potencialmente facilitadora da aprendizagem significativa;

- Participante 2: Aprender novas formas de avaliar o educando de forma qualitativa e ao longo do processo;

- Participante 3: Vivenciar uma sequência didática, fundamentada em teorias de aprendizagem, particularmente a da aprendizagem significativa;

- Participante 4: Fazer o aluno se aproximar de situações reais;

- Participante 5 (Professor): Porque trabalho com ensino de graduação e procuro novas estratégias para motivar os alunos na aprendizagem.

b) Quais as suas expectativas com a oficina?

- Participante 1: Poder aplicar/construir com minhas turmas uma UEPS para motivar e potencializar a aprendizagem.

- Participante 2: Participar da oficina para qualificar minha formação. 
- Participante 3: Aprender o método apresentado na oficina da Vitrine Tecnológica.

- Participante 4: Espero conseguir vivenciar a oficina de maneira a aprender esta abordagem, que para mim nova, a fim de - futuramente - utilizá-la para mais bem cumprir meu papel de educador.

- Participante 5: Melhorar minha forma de perceber as prioridades didáticas, podendo atingir a aprendizagem significativa.

Ao término da oficina, foi aplicado mais um questionário para verificar se os anseios e os objetivos dos participantes foram atingidos.

a) Você conhecia a estratégia apresentada na oficina?

- $80 \%$ dos participantes responderam que não conheciam esse método.

b) A oficina realizada contribuiu para a sua prática pedagógica?

- Todos os participantes responderam que sim, contribuiu ao seu fazer pedagógico.

c) É possível aplicar a estratégia apresentada na oficina na sua prática diária?

- Todos os participantes responderam que sim.

d) Sobre a oficina, pontue de (1) pouco a (5) muito, os seguintes aspectos da oficina:

Quadro 2: Opinião dos participantes da pesquisa

\begin{tabular}{|l|c|c|c|c|c|}
\hline Perguntas & 1 & 2 & 3 & 4 & 5 \\
\hline Informações fornecidas & & & & & $\mathrm{x}$ \\
\hline Qualidade do Material & & & & & $\mathrm{x}$ \\
\hline Relevância do assunto & & & & & $\mathrm{x}$ \\
\hline Atividade proposta & & & & & $\mathrm{x}$ \\
\hline Grau de satisfação da Vitrine & & & & & $\mathrm{x}$ \\
\hline
\end{tabular}

Fonte: Os autores.

Todos os cinco participantes avaliaram de forma satisfatória a organização das atividades promovidas na Vitrine Tecnológica. Por meio da análise dos resultados, fica extremamente fácil concluir que a metodologia teve uma excelente aceitação por parte dos alunos e fica evidente que a proposta auxiliou no processo ensino - aprendizagem, despertando interesse e motivação nos estudantes através do conteúdo relacionado ao equilíbrio químico. 
As atividades de experimentação com materiais alternativos no ensino são práticas docentes de um ensino direcionado à construção do conhecimento aliada ao desenvolvimento de atitudes de cooperação social.

\section{Considerações finais}

Esse trabalho propôs uma forma de se trabalhar conteúdos além do modelo tradicional de ensino e aprendizagem, baseado apenas em aulas expositivas. Para tanto, é necessário adequar os planos de aula a outros métodos de aprendizagem. Toda mudança- inicialmente- gera um desconforto, mas é necessário romper com paradigmas e mudar os rumos das metodologias de ensino e aprendizagem. Para isso, é necessário começar a transformar aos poucos os métodos de aplicação do ensino em sala de aula e, talvez futuramente, ter uma educação com mais qualidade para todos.

O experimento tornou mais fácil a aprendizagem, uma vez que os participantes observaram, manipularam e questionaram o que estava sendo pesquisado. Isso reforça a necessidade de aulas experimentais, tanto de química como de outras disciplinas, para uma melhor aprendizagem dos temas abordados no ensino. As atividades permitiram colocar os alunos no centro do processo ensino-aprendizagem, como elementos ativos, desenvolvendo uma visão além da "caixa" que delimita os procedimentos tradicionais utilizados em aulas experimentais, facilitando a aprendizagem dos fenômenos envolvidos no método estudado. Ademais, foram produzidos experimentos de baixo custo que permitiram determinações analíticas com exatidão e precisão aceitáveis. Além dos conhecimentos específicos da disciplina, outras habilidades foram trabalhadas como o trabalho em equipe, a socialização e a comunicação. Com a aplicação da cinza de casca de arroz, observou-se um maior volume de água armazenada pela sílica; consequentemente, maior foi o desenvolvimento e crescimento da planta de soja, resultando num aumento da produtividade desta cultura. Fica evidente-pelos resultados obtidos-que a proposta auxiliou no processo ensino-aprendizagem ao despertar interesse e a motivação dos estudantes para 0 conteúdo de equilíbrio químico. Assim, está UEPS é uma possibilidade que pode ser explorada em sala de aula para a obtenção de bons resultados de forma descontraída, de modo a desenvolver competências pessoais e coletivas de um grupo de alunos. 


\section{Potentially Significant Teaching Unit through experiments with rice husk ash}

\section{Abstract}

This paper presents the use of rice husk ash in soybean production as a "Unidade de Ensino Potencialmente Significativa - UEPS" (Potentially Significant Teaching Unit), and its application in Science / Chemistry teaching. It is a teaching methodology aimed at learning, with more participative and active students in class, and the teacher as an integral part of this process. The application of this strategy also contributes to overcome traditional learning, still quite present in classes. Targets to build a UEPS in order to facilitate the meaningful learning of the chemical equilibrium reaction involving water molecules and silica incorporated into the soil at different doses.

Keywords: UEPS. Rice Husk Ash. Teaching.

\section{Referências}

AUSUBEL, David Paul. A aprendizagem significativa: a teoria de David Ausubel. São Paulo: Moraes, 1982.

AUSUBEL, David Paul. Aquisição e retenção de conhecimentos: uma perspectiva cognitiva. Lisbon: Plátano, 2000.

BERTRAND, J. Will M.; FRANSOO, Jan C. Operations management research methodologies using quantitative modeling. International Journal of Operations \& Production Management, v. 22, n. 2, p. 241-264, 2002.

CARDOSO, Sheila P.; COLINVAUX, Dominique. Explorando a Motivação para Estudar Química. Química Nova, São Paulo, v. 3, n. 23, p. 401-404, 2000.

CONAB. Acompanhamento da safra brasileira de grãos, Brasília, v. 6, n. 9, p. 1-113, 2019.

DELLA, Viviana Possamai; KÜHN, Ingeborg; HOTZA, Dachamir. Reciclagem de Resíduos Agro - Industriais: Cinza de Casca de Arroz como Fonte Alternativa de Sílica. Cerâmica Industrial, São Paulo, v. 10, n. 2, p. 22-25, mar./abr. 2005.

DONEGA, Mateus Augusto; VOLK, Leandro Bochi da Silva; NOLLA, Antonio; GAVIOLLI, Thiago de Oliveira. O. Avaliação do uso de casca de arroz carbonizada no desenvolvimento do sistema radicular do milho (Zea mays L.). In: CONGRESSO BRASILEIRO DE CIÊNCIA DO SOLO, 31, 2007, Gramado. Anais[...]. Viçosa: SBCS, 2007.

FOLETTO, Edson L.; HOFFMANN, Ronaldo; HOFMANN, Rejane S.; PORTUGAL Jr., UtinguassúL.; JAHN, Sérgio L. Aplicabilidade das Cinzas da Casca de Arroz. Química Nova, v. 28, n. 6, p. 1055-1060, 2005.

FREIRE, Paulo. Pedagogia da Autonomia. São Paulo: Paz e Terra, 1997. 
GEORGE-WILLIAMS, Stephen R.; KARIS, Dimitri; ZIEBELL, Angela L.; KITSON, Russell R. A.; COPPO, Paolo; SCHMID, Siegbert; THOMPSON, Christopher D.; OVERTON, Tina L. Investigating student and staff perceptions of students' experiences in teaching laboratories through the lens of meaning full earning. Chemistry Education Research and Practice, v. 20, n. 1, p. 187-196, 2019.

GIL, Antonio Carlos. Como elaborar projetos de pesquisa. São Paulo: Atlas, 2002.

GOMES, Fábio B.; MORAES, Jair C.; SANTOS, Custódio D. dos; ANTUNES, Cristiana S. Uso de silício como indutor de resistência em batata a Myzuspersicae (Sulzer) (Hemiptera: Aphididae). Neotropical Entomology, Londrina, v. 37, n. 2, p.185-190, mar./abr. 2008.

GUIMARÃES, Cleidson Carneiro. Experimentação no Ensino de Química: Caminhos e Descaminhos Rumo à Aprendizagem Significativa. Química Nova na Escola, São Paulo, v. 31, n. 3, p. 198-202, ago. 2009

HORN, Priscila Aparecida. Práticas com materiais alternativos no ensino da Química: uma nova percepção. 2011. Trabalho de Conclusão de Curso (Licenciatura em Química) -Coordenação de Química, Universidade Tecnológica Federal do Paraná, Pato Branco,2011.

ISLABÃO, Gláucia Oliveira. Uso de cinza de casca de arroz como corretivo e condicionador do solo. 2013. Tese (Doutorado em Química) - Faculdade de Agronomia, Universidade Federal de Pelotas, Pelotas, 2013.

KATO, Naoto; OWA, Naoto. Dissolution of slag fertilizers in a paddy soil and Si uptake by rice plant. Soil Science and Plant Nutrition, v. 43, p. 329-341, 1997.

KRAUSKOPF, Konrad Bates. Introdução à geoquímica. São Paulo: Polígono/EDUSP, 1972.

MORAES, Roque; RAMOS, Maurivan Güntzel. Construindo o conhecimento: uma abordagem para o ensino de ciências. Porto Alegre: Sagra Luzzato, 1988.

MOREIRA, M.A. (2011a). Unidades de Enseñanza Potencialmente Significativas-UEPS. Aprendizagem Significativa em Revista. Porto Alegre, v.1,n. 2,p.43-63.

MOREIRA, M.A. (2011b). Aprendizagem significativa: um conceito subjacente. Aprendizagem significativa em Revista, v. 1, n. 3, p. 25-46.

MOREIRA, M.A. (2011c). Meaningful learning: from the classical to the critical view. Aprendizagem Significativa em Revista, v. 1, p. 1-15.

NETO, E. R. O estado da arte do uso da cinza de casca de arroz. Santa Catarina: 2007.

OLIVEIRA, Antonio Pedro Novaesde; MONTEDO, OscarRubemKlegues; JUNKES, JanaínaAccordi; SAGRILLO, Viviana Possamai Della; HOTZA, Dachamir. Obtenção de sílica amorfa a partir da casca de arroz. Depositante: Senai/Ctcmat - Centro de Tecnologia Em Materiais. Procurador: Edemar Soares Antonini. PI 0504966-0 A. Depósito: 31 out. 2005. Concessão: 7 ago. 2007.

OLIVEIRA, Maria Marly de. Como fazer projetos, relatórios, monografias, dissertações e teses. Rio de Janeiro: Elsevier, 2013.

QUIRINO, Waldir F; VALE, Ailton Teixeira do; ANDRADE, Ana Paula Abreu de; ABREU, Vera Lúcia Silva; AZEVEDO, Ana Cristina dos Santos. Poder calorífico da madeira e de materiais ligno-celulósicos. Revista da Madeira, n. 89, p. 100-106, abr. 2005. 
RODRIGUES, Fabrício de Ávila; OLIVEIRA, Lilian Aparecida de; KORNDÖRFER, Ana Paula; KORNDÖRFER, Gaspar Henrique. Silício: um elemento benéfico e importante para as plantas. Informações Agronômicas, n. 134, p. 14-20, jun. 2011.

SANDRINI, Willian Costa. Alterações químicas e microbiológicas do solo decorrentes da adição de cinza de casca de arroz. 2010. Dissertação (Mestrado em Agronomia) - Programa de Pós-Graduação em Agronomia, Universidade Federal de Pelotas, Pelotas, 2010.

SANTIN, M. J.; VAHL, L. C. Aproveitamento da cinza da casca de arroz como corretivo da acidez e da fertilidade do solo. Relatório CNPQ. Processo: 11.3006/83.AG.1985.

SILVA, Monique Murielle de Araújo. Aplicação de recursos alternativos em aulas experimentais de química no ensino médio na cidade de Angicos-RN. 2013. Monografia (Bacharel em Ciência e Tecnologia) - Departamento de Ciências Exatas, Universidade Federal Rural do Semi-Árido,Angicos, 2013.

TURRIONI, João Batista; MELLO, Carlos Henrique Pereira. Metodologia de pesquisa em engenharia de produção: Estratégias, métodos e técnicas para condução de pesquisas quantitativas e qualitativas. 2012. Monografia (Pós-Graduação em Engenharia de Produção) - Programa de Pós-Graduação em Engenharia de Produção, Universidade Federal de Itajubá, Itajubá, 2012.

VALE, A. T. do; ABREU, V. L. S.; GONÇALEZ, J. C.; COSTA, A. F. da. Estimativa do poder calorífico superior do carvão vegetal de madeiras de Eucalyptus grandis em função do teor de carbono fixo e do teor de materiais voláteis. Brasil Florestal, Brasília, v. 21, n. 73, p. 47-52, abr. 2002. 